\title{
Relationship between the foot progression angle and eversion and exercise-related lower leg pain
}

\author{
Tine M Willems ${ }^{1 *}$, Erik Witvrouw ${ }^{1}$, Dirk De Clercq² ${ }^{2}$ Philip Roosen ${ }^{1}$ \\ From 3rd Congress of the International Foot and Ankle Biomechanics Community \\ Sydney, Australia. 11-13 April 2012
}

\begin{abstract}
Background
In clinical practice, out-toeing is often linked with an increased eversion and an increased medial pressure distribution. However, in the literature, there is little evidence for this relationship. On the other hand, as an increased eversion and an increased medial pressure distribution have been detected as risk factors for exerciserelated lower leg pain (ERLLP) [1,2], and if the foot progression angle is related to these parameters, the occurrence of ERLLP could be due to an increased foot progression angle. The purpose of this study was therefore 1) to investigate the relationship between the foot progression angle and the amount of eversion and the medio-lateral pressure distribution and 2) to check if the foot progression angle is a risk factor for ERLLP.
\end{abstract}

\section{Materials and methods}

3D gait kinematics combined with plantar pressure profiles were collected from 400 healthy physical education students. After this evaluation, all sports injuries were registered by a sports physician during 3 years. Relationship between foot progression angle and the amount of eversion and the medio-lateral pressure distribution were tested with Pearson correlation. Cox regression analysis was used to investigate the effect of the foot progression angle on the development of ERLLP.

\section{Results}

Forty-six subjects developed ERLLP and 29 of them developed bilateral symptoms thus giving 75 symptomatic lower legs. Bilateral lower legs of 167 subjects who developed no injuries in the lower extremities served as controls. Pearson correlation showed no significant correlation between the foot progression angle and the eversion excursion $(R=.121)$ and the medio-lateral pressure distribution $(R=.116)$. Cox regression analysis showed no significant differences for the foot progression angle between the injured and uninjured subjects.

\section{Conclusions}

The findings of this study suggest that the foot progression angle is not a risk factor for ERLLP as the foot progression angle is not related to the amount of eversion and the medio-lateral pressure distribution.

\section{Author details}

'Department of Rehabilitation Sciences and Physiotherapy, Ghent University, Ghent, 9000, Belgium. ${ }^{2}$ Department of Movement and Sport Sciences, Ghent University, Ghent, 9000, Belgium.

Published: 10 April 2012

\section{References}

1. Willems TM, De Clercq D, Delbaere K, et al: A prospective study to gait related risk factors for exercise-related lower leg pain. Gait Posture 2006, 23:91-98.

2. Willems TM, Witvrouw E, De Cock A, et al: Gait-related risk factors for exercise-related lower-leg pain during shod running. Med Sci Sports Exerc 2007, 39:330-339.

doi:10.1186/1757-1146-5-S1-044

Cite this article as: Willems et al:: Relationship between the foot progression angle and eversion and exercise-related lower leg pain. Journal of Foot and Ankle Research 2012 5(Suppl 1):O44.

\footnotetext{
* Correspondence: tine.willems@ugent.be

'Department of Rehabilitation Sciences and Physiotherapy, Ghent University, Ghent, 9000, Belgium

Full list of author information is available at the end of the article
}

(c) 2012 Willems et al; licensee BioMed Central Ltd. This is an Open Access article distributed under the terms of the Creative Commons 